Pediatr. Res. 14: 965 (1980)

\title{
Letter to the Editor: Growth Cartilage of Diastrophic Dwarfism
}

\author{
V. STANESCU, R. STANESCU, AND P. MAROTEAUX ${ }^{(4)}$ \\ Hopital des Enfants Malades, 75730. Paris Cedex 15, France
}

In a recent article in this journal on the endochondral growth plate of "diastropic dwarfism" (diastrophic dysplasia), Horton et al. (1) wrote that the abnormalities of this cartilage have never been reported in detail. However, in a monograph published in 1977 (3) and quoted by Horton et al. (1), we described in detail the abnormalities observed in the cartilage of patients with diastrophic dysplasia. The study was performed in three typical cases and in two less severely affected patients (diastrophic variant). Growth cartilage specimens were obtained by biopsy during orthopedic surgery. Histologic and histochemical examination was performed on fresh frozen and semithin Spurr-embedded sections, and electron microscopic study was carried out on ultrathin sections. Material obtained from freeze-dried, microdissected sections was used for the gel electrophoretic study of $\alpha$-chains and $\mathrm{CNBr}$ derived peptides of collagen and of proteoglycan subunits.

The abnormalities of the distribution of the metachromatic material as well as the histologic and ultrastructural abnormalities of collagen organization were described in detail (Ref. 3, Figs. 54 to 61). The microchemical studies showed a normal electrophoretic migration of proteoglycan subunits. The collagen analysis showed in severe cases a detectable amount of type I collagen besides the usual type II collagen. Two pathogenic hypothesis were discussed: a primary cell degeneration with secondary matrix alterations or an abnormality of collagen metabolism with secondary cell death. All these data and hypotheses were included also in a large

Copyright (C) 1980 International Pediatric Research Foundation. Inc. 0031-3998/80/1408-0965\$02.00/0 paragraph of the English summary of our study. Furthermore, in a previous paper (2), we had described the abnormal distribution of the metachromatic material in the matrix and abnormalities of hexosamine content in isolated histologic zones of growth cartilage of diastrophic dysplasia.

We were therefore rather surprised to read in the discussion of the article of Horton $e t$ al. that our study and other studies from the literature mention only "the marked degeneration resting chondrocytes in cartilage matrix" and that "in addition" Horton et al. identified "histochemical abnormalities of two of the major components of cartilage matrix, collagen and proteoglycan."

We think that a proper quotation of the existing data is necessary for a better understanding of the topics discussed and for a proper information of the readers.

\section{REFERENCES AND NOTES}

1. Horton, W. A., Rimoin, D. L., Hollister, D. W., and Silberberg, R.: Diastrophic dwarfism: a histochemical and ultrastructural study of the endochondral growth plate. Pediatr. Res., 13: 904 (1979).

2. Stanescu, V.. Stanescu, R., and Maroteaux, P.: Etude histochimique et microchimique du cartilage de croissance tibial dans le nanisme diastrophique et la pycnodysostose. Ann. Histochim., 18: 179 (1973)

3. Stanescu, V., Stanescu, R., and Maroteaux, P.: Etude morphologique et biochimique du cartilage de croissance dans les ostéochondrodysplasies. Arch. Fr. Pediatr., 34: 1 (1977).

4. Requests for reprints should be addressed to: Dr. Pierre Maroteaux, Hopital des Enfants Malades, 149, Rue de Sevres, 75730 Paris Cedex 15, France.

Printed in U.S.A. 